\title{
Pyopneumothorax from coinfection by Trichomonas tenax and Geotrichum capitatum in a child from China: a case report
}

\author{
Yuhui Wu ${ }^{1}$, Yuanzhen Ye ${ }^{2^{*}}$, Yanlan Yang ${ }^{1}$, Weiguo Yang ${ }^{1}$, Jiayin Lin ${ }^{1}$ and Ke Cao ${ }^{3^{*}}$
}

\begin{abstract}
Background: Trichomonas tenax may appear in the oral cavity of humans due to poor dentition or oral hygiene. Pyopneumothorax is a serious complication of lower respiratory tract infections that very rarely can be caused by a trichomonad species in predisposed individuals. We report a rare case of pleurisy due to T. tenax with coinfection by a fungus.

Case presentation: We describe a 16-year-old patient with cerebral palsy who presented with severe pyopneumothorax. T. tenax was identified by microscopic examination of the pleural effusion and next-generation sequencing. We also identified Geotrichum capitatum in the pleural effusion and bronchoalveolar lavage fluid cultures. Treatment with voriconazole and metronidazole successfully eliminated these pathogens and relieved the clinical symptoms. A literature review indicated this is the first reported case of pleurisy due to T. tenax with coinfection by a fungus.
\end{abstract}

Conclusion: The rarity of pyopneumothorax caused by T. tenax coinfection with a fungus should not be overlooked in the clinic. These patients should be and treated in a timely manner.

Keywords: Pyopneumothorax, Pleural effusion, Protozoa, Trichomonas

\section{Background}

Humans are common hosts of three different trichomonad species, the genitourinary Trichomonas vaginalis, the oral T. tenax, and the intestinal Pentatrichomonas hominis. T. tenax may appear in the human oral cavity due to poor dentition and hygiene. There are only rare reports of pulmonary infections by this species [1-7]. Pyopneumothorax is a serious complication of pulmonary infection. To our knowledge, there are only 7 reported cases of T. tenax infection and pleural empyema in the English-language medical literature to date [1-7].

\footnotetext{
*Correspondence: 170127625@qq.com; yypk3141@126.com

2 Department of Neurology, Shenzhen Children's Hospital, 7019\# Yitian

Road, Shenzhen 518038, Guangdong, People's Republic of China

${ }^{3}$ Department of Laboratory Medicine, Shenzhen Children's Hospital,

Shenzhen, China

Full list of author information is available at the end of the article
}

Herein, we describe a patient with pyopneumothorax with coinfection by T. tenax and Geotrichum capitatum, a saccharomycete fungus formerly known as Trichosporon capitatum or Brastochizomyces capitatus. Our review of the characteristics of this patient's condition and relevant literature may aid in future recognition of this condition.

\section{Case presentation}

A 16-year-old boy with cerebral palsy who lived in a social welfare institute presented to the Pediatric Intensive Care Unit of our hospital. He had a 4-day history of persistent fever, respiratory distress, productive cough, and decreased appetite. Before admission, the local hospital administered ceftriaxone for 3 days due to a suspected bacterial infection, but the fever persisted. On physical examination and $2 \mathrm{~h}$ after taking ibuprofen, his temperature was $37.1{ }^{\circ} \mathrm{C}$, heart rate was 137 beats/min, 
blood pressure was $137 / 78 \mathrm{mmHg}$, respiration rate was 42 breaths/min, and the saturation of pulse oximetry was $96 \%$ with an oxygen mask. The patient had poor oral hygiene but no lip cyanosis, decreased right lung respiratory movement, dullness on percussion and decreased breathing sounds over his right chest, but no rales. The results of an abdominal examination were unremarkable.

The laboratory results at admission indicated a peripheral white blood cell count of $27.15 \times 10^{9} / \mathrm{L}$ with $80.6 \%$ neutrophils, $0.01 \times 10^{9} / \mathrm{L}$ eosinophils, $48 \mathrm{~g} / \mathrm{dL}$ hemoglobin, a hematocrit of $13.6 \%$, and $442 \times 10^{9} / \mathrm{L}$ platelets. The level of C-reactive protein was $323.93 \mathrm{mg} / \mathrm{L}$ and the level of procalcitonin was $40.62 \mathrm{ng} / \mathrm{mL}$. Analysis of liver function indicated the alanine aminotransferase was $51 \mathrm{IU} / \mathrm{L}$, aspartate aminotransferase was $95 \mathrm{IU} / \mathrm{L}$, total bilirubin was $90.7 \mu \mathrm{mol} / \mathrm{L}$, direct bilirubin was $63.2 \mu \mathrm{mol} / \mathrm{L}$, albumin was $24.2 \mathrm{~g} / \mathrm{L}$, and lactate dehydrogenase was $1326 \mathrm{IU} / \mathrm{L}$. The patient's serum ammonia level was $181.6 \mu \mathrm{mol} / \mathrm{L}$ and the serum lactate level was $2.02 \mathrm{mmol} / \mathrm{L}$. A chest radiograph and subsequent computed tomography (CT) indicated bilateral pneumonia and a large amount of pyopneumothorax in the right pleural cavity, blunting of the right costophrenic angle, oblique fissure hydrothorax on the left, and a small amount of hydrothorax in the abdominal cavity (Fig. 1).

We subsequently initiated empirical anti-infection treatment with imipenem and cilastatin and performed a thoracostomy of the right chest cavity for drainage. A macroscopic examination indicated the pleural effusion was purulent and foul-smelling. The patient's respiratory status improved after drainage of $300 \mathrm{~mL}$ of the pleural effusion. We also collected bronchoalveolar lavage fluid using fiber optic bronchoscopy, and sent drainage from the empyema to the microbiology laboratory for smear and culture testing.
Microbiological analysis of the pleural fluid showed a white blood cell count of $438,000 / \mu \mathrm{L}$ with $92 \%$ polymorphonuclear leukocytes and a positive Rivalta test. Direct microscopy of a wet smear cytocentrifuged preparation created with $100 \mu \mathrm{L}$ of the pleural fluid sediment indicated motile and flagellated organisms that were 8-10 $\mu \mathrm{m}$ in length. We made a preliminary identification of T. tenax based on their typical morphology, size, and wobbly and rolling motility (Fig. 2a, b) which is consistent with previous descriptions of $T$. tenax $[7,8]$. The subsequent next-generation sequencing (NGS) of the pleural effusion confirmed this identification. For NGS, a $6 \mathrm{~mL}$ sample of pleural effusion was collected and was first enriched $(\sim 200 \mu \mathrm{L})$ using centrifugation (3000 rpm, $10 \mathrm{~min}, 4^{\circ} \mathrm{C}$ ). This enriched sample was used for nucleic acid extraction by Guangzhou Sagene Biotech Co. (Guangzhou, China). The metagenomic library was constructed using the protocol of the Nextera XT kit (Illumina, USA). Sequencing was performed using an Illumina Nextseq 550 DX sequencing platform. Raw data were filtered using FastQC software, human related reads were removed by aligning with a human genome reference sequence (version: GRCh38) using BWA (http://biobwa.sourceforge.net/) software, and then a proprietary pathogenic microbial database (including about 15,000 medical microbiological samples, optimized by Guangzhou Sagene Biotech Co., Ltd.) was used for analysis. There were $8,126,928$ total raw reads, and non-human reads accounted for $44.52 \%$ of this total. Most of these reads could not be classified or mapped to any organisms in the BLAST nt database, and a small number of these reads were categorized as contaminating background reads (based on comparison to a negative control) and were filtered out. There were 178 reads of $T$. tenax and 3362 reads of $G$. capitatum. Regarding parasites and

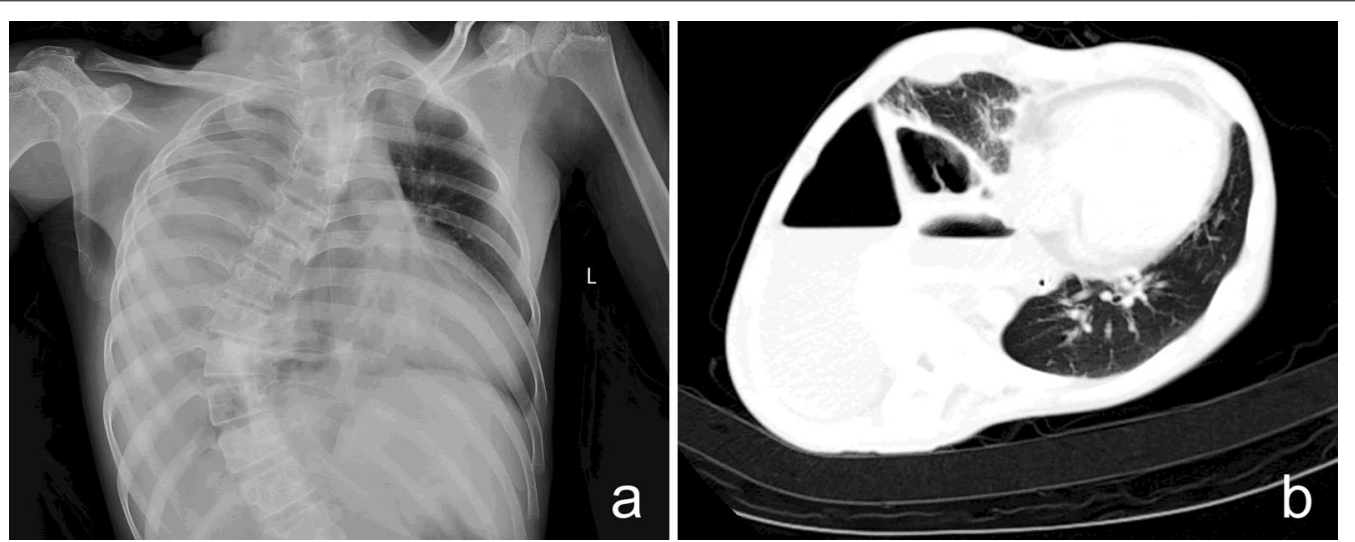

Fig. 1 a Chest radiography on admission, showing massive right pleural effusion with blurred left heart border. $\mathbf{b}$ Chest CT at 2 days after admission, showing bilateral pneumonia, a large pyopneumothorax in the right pleural cavity, and an oblique fissure hydrothorax on the left 


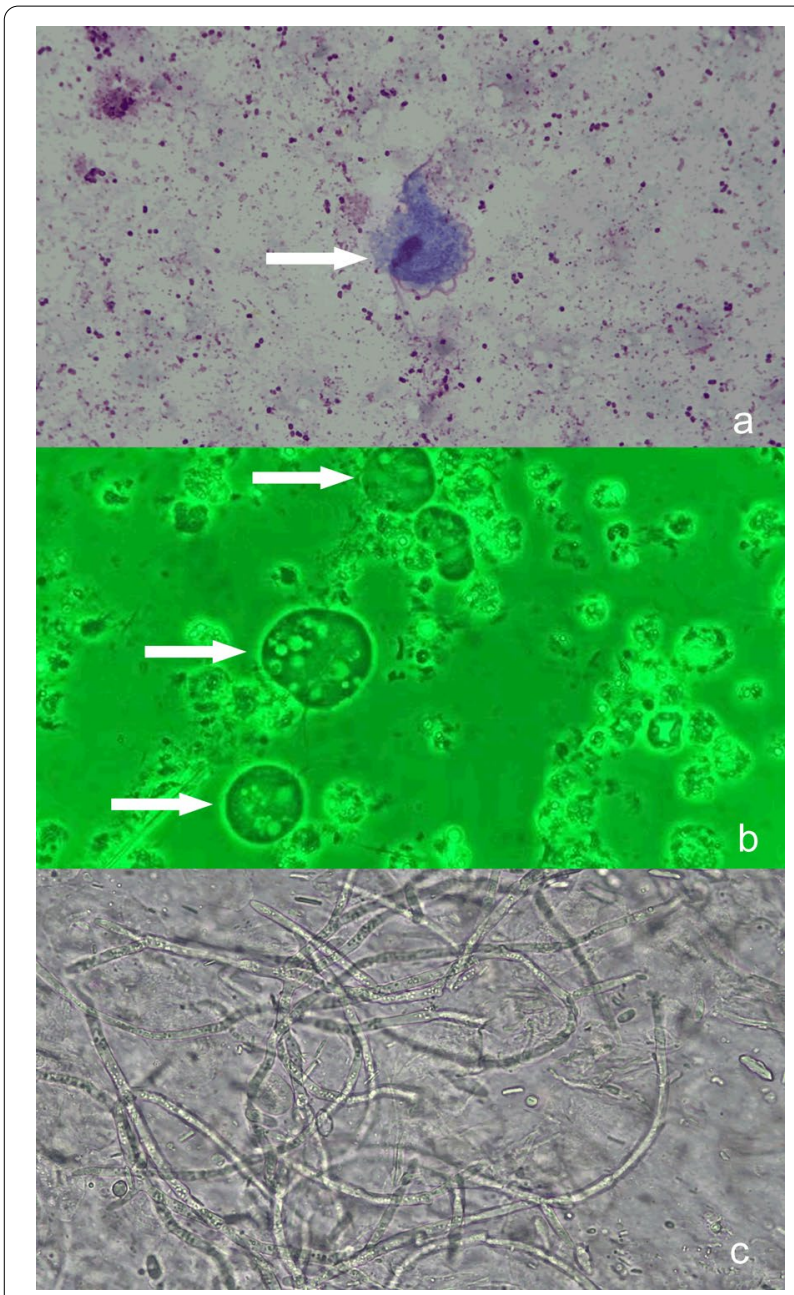

Fig. 2 a Bright-field microscopy with Wright's-Giemsa staining ( $\times 1000)$. b Phase-contrast microscopy of a sample taken during exercise (wet smear, $\times 1000$ ). As indicated by the arrows, the 4

characteristic free anterior flagella, nucleus, and axial column of the T. tenax trophozoites were well stained. The undulating membrane is shorter than the long axis of the trophozoite, and accounts for about half of the whole trophozoite body. The slender axial column runs through the trophozoite and extends out of the body from the back, and the axostyle is relatively thick. The nucleus is located in the anterior part of the trophozoite, and has an oval shape with many chromatin granules. c Sputum smear, showing a large number of hyphae from G. capitatum (× 1000)

fungi, more than 10 reads in sterile body fluids (pleural effusion in this case) should be considered as "positive" according to the "Chinese expert consensus on metagenomics next-generation sequencing application on pathogen detection of infectious diseases in 2021" and other publications [9-11]. The raw data was submitted to the NCBI SRA database (accession number PRJNA738659). We also observed fungal spores and hyphae in the smear. Cultures of the pleural effusion and bronchoalveolar lavage fluid yielded G. capitatum (104 cfu/mL; Fig. 2c) based on mass spectrometry. There were no trichomonads in wet smears from washings of the oral cavity, no trichomonad cultures were performed, and the blood culture findings were negative.

Based on these findings, we switched the therapy to intravenous metronidazole (for T. tenax) and voriconazole (for G. capitatum). The patient's temperature returned to normal 4 days later and $T$. tenax was not detectable after 3 days. However, one week later the boy again developed a fever. A subsequent chest tube drainage failed to resolve the effusion and a follow-up chest CT showed inadequate clearing of the pleural effusion. Thus, we performed further surgical cleaning of the pleural cavity and video-assisted thoracoscopic decortication. The patient's temperature gradually returned to normal within 3 days after this treatment regimen. On day 18 , we removed the pleural tube, and a follow-up chest $x$-ray showed clearing of pleural effusion. We subsequently discharged the patient on day 24, when he was in stable condition. A follow-up examination on day 30 indicated he remained in good health.

\section{Discussion and conclusions}

Trichomonads are microscopic protozoa with four free flagella and a fifth flagellum associated with the edge of the undulating membrane. Detection is primarily by direct microscopic examination of fresh specimens, and only rarely by culture because it is usually unsuccessful. Gram staining is problematic because the fixation process destroys most of their characteristic morphologic features, making identification difficult [12]. As such, preliminary direct microscopic examinations of wet smears from freshly collected clinical samples are generally necessary for detecting these organisms, which are characterized by rapid, wobbly, and rolling motility. Results from the polymerase chain reaction and other molecular biology techniques suggest that trichomonad infections were substantially underestimated during past decades [13]. We performed direct microscopy of a wet smear cytocentrifuged preparation created with $100 \mu \mathrm{L}$ of sediment of the pleural fluid and indentified motile and flagellated organisms that were $8-10 \mu \mathrm{m}$ in length. We initially identified these organisms as $T$. tenax based their morphology, size, and wobbly and rolling motility, which is consistent with previous descriptions $[7,8]$. We subsequently confirmed this identification using NGS.

Trichomonas tenax is a very important species among the trichomonads that can infect humans. It was once regarded as a harmless commensal of the oral cavity due to poor oral hygiene and dentition or periodontal disease, but this is currently debatable $[8,14]$. T. tenax is the most common cause of trichomonad pulmonary infections, 
and it apparently gains entry to the lower respiratory tract by aspiration of oropharyngeal secretions. Most trichomonad infections occur in patients who are compromised by an underlying condition, such as chronic pulmonary disease, immunosuppression, human pneumocystis pneumonia, or acute respiratory distress syndrome, but infections can also occur in healthy people [15-17].

To the best of our knowledge, there are only 7 previous cases of T. tenax in the pleural cavity (Table 1) [1-7]. Notably, all 7 of these patients had coinfection of T. tenax with a bacterial species. It is thus likely that $T$. tenax is probably unable to proliferate and cause pulmonary disease or thorax empyema by itself, because it requires coinfection by an aerobic or anaerobic bacterial species as a food source. These protozoa require favorable microaerophilic conditions $[18,19]$. The findings that all previous cases involving T. tenax infection of the pleural cavity were mixed infections with bacteria and that metronidazole relieved the clinical symptoms in these patients suggest that this trichomonad has moderate pathogenicity, and is not entirely harmless to humans.

The patient described here is the first reported case of pleurisy caused by infection with T. tenax and a fungus (G. capitatum) rather than a bacterium. Kurnatowska and colleagues collected a sample of 936 dental patients with different diagnoses and identified T. tenax in 90 cases, including 85 cases where it co-occurred with fungi. A similar finding was reported in a patient with sinusitis [20]. This result confirms that T. tenax may appear in humans as mixed infections with fungi, and that the prevalence of such coinfections may be underestimated [21]. The examination of our patient's pleural effusion, bronchoalveolar lavage fluid, and blood specimens indicated no bacterial species. It is possible that $T$. tenax and G. capitatum were both insensitive to the initial antibiotics, and that the fungus provided a microenvironment to support the growth of T. tenax.
Because the rarity of pleural trichomonad infections in the clinic, they may be easily overlooked. The potential occurrence of trichomonads should therefore be considered and included in the differential diagnosis of pleural effusion in high-risk patients. Microscopic examination of a wet smear is usually successful in detection of trichomonads. The clinical application of modern molecular techniques, including the polymerase chain reaction and NGS, greatly aids in the diagnosis and identification at the species level $[6,13]$. Our patient had a favorable response to metronidazole, a drug commonly used for $T$. vaginalis infections [22], and this supports our interpretation that T. tenax was a coinfecting agent that contributed to the patient's pathology.

\section{Abbreviations \\ T. tenax: Trichomonas tenax; NGS: Next-generation sequencing; CT: Computed tomography; G. capitatum: Geotrichum capitatum}

\section{Acknowledgements \\ We thank the patient for his participation and cooperation.}

\section{Authors' contributions}

YZY and KC performed the experiments, participated in the design of the study. WY drafted the manuscript and participated in the microscopic examination of the trophozoite. YLY and JL participated in the case collection. YZY participated in the revision of the manuscript. WY conceived and designed the experiments. All authors read and approved the final manuscript.

\section{Funding}

This work was supported by the Sanming Project of Medicine in Shenzhen (SZSM201812005); Shenzhen Fund for Guangdong Provincial High level Clinical Key Specialties (No. SZGSP012); and Shenzhen Key Medical Discipline Construction Fund (No. SZXK033). The funding bodies had no role in the design of the study, the collection, analysis, or interpretation of the data, or writing the manuscript.

\section{Availability of data and materials}

The datasets used and/or analyzed during the current study are available from the corresponding author on reasonable request.

\section{Declarations}

Ethics approval and consent to participate Not applicable.

Table 1 Clinical characteristics of the 8 cases of Trichomonas tenax associated pleural empyema

\begin{tabular}{|c|c|c|c|c|c|c|c|}
\hline No. & Age/sex & Underlying disease(s) & $\begin{array}{l}\text { Coinfection } \\
\text { pathogen }\end{array}$ & $\begin{array}{l}\text { Immunosuppressive } \\
\text { therapy }\end{array}$ & Treatment & Outcome & References \\
\hline 1 & $87 / M$ & Chronic pulmonary disease & Bacteria & No & MTZ, TET & Clinical improvement & {$[1]$} \\
\hline 2 & 70/M & Alcohol abuse & Bacteria & No & MTZ, CEF & Clinical improvement & {$[2]$} \\
\hline 3 & $53 / \mathrm{M}$ & $\begin{array}{l}\text { Acromegaly rectal adenocar- } \\
\text { cinoma }\end{array}$ & Bacteria & $\begin{array}{l}\text { Chemotherapy, corticother- } \\
\text { apy, cobalt irradiation }\end{array}$ & MTZ & Clinical improvement & {$[7]$} \\
\hline 4 & $59 / \mathrm{M}$ & Lung adenocarcinoma & Bacteria & Corticotherapy & MTZ, GEN and CIP & Death & {$[3]$} \\
\hline 5 & $58 / \mathrm{M}$ & Oesophagus adenocarcinoma & Bacteria & No & MTZ, PTZ and GEN & Death & {$[4]$} \\
\hline 6 & $33 / \mathrm{F}$ & Heart transplantation & Bacteria & Yes & MTZ, PTZ & Clinical improvement & {$[5]$} \\
\hline 7 & $67 / F$ & Glioblastomahigh & Bacteria & Corticotherapy & MTZ & Death & {$[6]$} \\
\hline 8 & $16 / M$ & Cerebral palsy & Fungus & No & MTZ & Clinical improvement & Our case \\
\hline
\end{tabular}




\section{Consent for publication}

Written informed consent was obtained from the legal guardian of the patient for publication of this Case Study and any accompanying images. A copy of the written consent is available for review by the editor of this journal.

\section{Competing interests}

The authors declare that they have no competing interests.

\section{Author details}

${ }^{1}$ Department of Pediatric Intensive Care Unit, Shenzhen Children's Hospital 7019\# Yitian Road, Shenzhen 518038, Guangdong, People's Republic of China. ${ }^{2}$ Department of Neurology, Shenzhen Children's Hospital, 7019\# Yitian Road, Shenzhen 518038, Guangdong, People's Republic of China. ${ }^{3}$ Department of Laboratory Medicine, Shenzhen Children's Hospital, Shenzhen, China.

Received: 24 April 2021 Accepted: 5 August 2021

Published online: 20 August 2021

\section{References}

1. Memik F. Trichomonads in pleural effusion. JAMA. 1968:204:1145-6.

2. Ohkura T, Suzuki N, Hashiguchi Y. Invasion of the human respiratory tracts by trichomonads. Am J Trop Med Hyg. 1985:34:823.

3. Porcheret $H$, Maisonneuve L, Estève V, Jagot JL, Le Pennec MP. Pleural trichomoniasis due to Trichomonas tenax. Rev Mal Respir. 2002;19:97-9.

4. Mallat H, Podglajen I, Lavarde V, Mainardi JL, Frappier J, Cornet M. Molecular characterization of Trichomonas tenax causing pulmonary infection. J Clin Microbiol. 2004:42:3886-7.

5. Bellanger AP, Cabaret O, Costa JM, Foulet F, Bretagne S, Botterel F. Two unusual occurrences of trichomoniasis: rapid species identification by PCR. J Clin Microbiol. 2008;46:3159-61.

6. Leterrier M, Morio F, Renard BT, Poirier AS, Miegeville M, Chambreuil G. Trichomonads in pleural effusion: case report, literature review and utility of PCR for species identification. New Microbiol. 2012:35:83-7.

7. Shiota T, Arizono N, Morimoto T, Shimatsu A, Nakao K. Trichomonas tenax empyema in an immunocompromised patient with advanced cancer. Parasite. 1998:5:375-7.

8. Marty M, Lemaitre M, Kémoun P, Morrier JJ, Monsarrat P. Trichomonas tenax and periodontal diseases: a concise review. Parasitology. 2017;144:1417-25.

9. Miao Q, Ma Y, Wang Q, Pan J, Zhang Y, Jin W, et al. Microbiological diagnostic performance of metagenomic next-generation sequencing when applied to clinical practice. Clin Infect Dis. 2018;67:S231-40.
10. Wilson MR, Sample HA, Zorn KC, Arevalo S, Yu G, Neuhaus J, et al Clinical metagenomic sequencing for diagnosis of meningitis and encephalitis. $N$ Engl J Med. 2019:380:2327-40.

11. Brown RS, Kertiles LP, Rosenfield C, Kleinmann RE, Crigler JF Jr. Thyrotropin-receptor autoantibodies in children and young adults with Graves' disease. Am J Dis Child. 1986;140:238-41.

12. Yao C, Ketzis JK. Aberrant and accidental trichomonad flagellate infections: rare or underdiagnosed? Trans R Soc Trop Med Hyg. 2018;112:64-72.

13. Benabdelkader S, Andreani J, Gillet A, Terrer E, Pignoly M, Chaudet H, et al. Specific clones of Trichomonas tenax are associated with periodontitis. PLOS ONE. 2019:14:e0213338.

14. Bracamonte-Wolf C, Orrego PR, Muñoz C, Herrera D, Bravo J, Gonzalez J, et al. Observational cross-sectional study of Trichomonas tenax in patients with periodontal disease attending a Chilean university dental clinic. BMC Oral Health. 2019;19:207.

15. Duboucher C, Barbier C, Beltramini A, Rona M, Ricome JL, Morel G, et al. Pulmonary superinfection by trichomonads in the course of acute respiratory distress syndrome. Lung. 2007;185:295-301.

16. Thomas CF Jr, Limper AH. Current insights into the biology and pathogenesis of Pneumocystis pneumonia. Nat Rev Microbiol. 2007;5:298-308.

17. Martínez-Girón R, Esteban JG, Ribas A, Doganci L. Protozoa in respiratory pathology: a review. Eur Respir J. 2008;32:1354-70.

18. Duboucher C, Gerbod D, Noël C, Durand-Joly I, Delgado-Viscogliosi P, Leclerc $C$, et al. Frequency of trichomonads as coinfecting agents in Pneumocystis pneumonia. Acta Cytol. 2005;49:273-7.

19. Duboucher C, Caby S, Pierce RJ, Capron M, Dei-Cas E, Viscogliosi E. Trichomonads as superinfecting agents in Pneumocystis pneumonia and acute respiratory distress syndrome. J Eukaryot Microbiol. 2006;53(Suppl 1):S95-7.

20. Tomás Camacho A, Pallas E, Silva J. Fungal-protozoal sinusitis. Enferm Infecc Microbiol Clin. 2001;19:399-400.

21. Kurnatowska AJ, Kurnatowski P. Trichomonosis of the oral cavity complicated by mycosis. Parassitologia. 1998;40:339-42.

22. Bala V, Chhonker YS. Recent developments in anti-Trichomonas research: an update review. Eur J Med Chem. 2018;143:232-43.

\section{Publisher's Note}

Springer Nature remains neutral with regard to jurisdictional claims in published maps and institutional affiliations.
Ready to submit your research? Choose BMC and benefit from:

- fast, convenient online submission

- thorough peer review by experienced researchers in your field

- rapid publication on acceptance

- support for research data, including large and complex data types

- gold Open Access which fosters wider collaboration and increased citations

- maximum visibility for your research: over 100M website views per year

At $\mathrm{BMC}$, research is always in progress.

Learn more biomedcentral.com/submissions 